\title{
Cytotoxic and Genotoxic Studies on the Mucus of Indian Volute Melo broderipii (Gmelin 1758) and Spider Conch Lambis lambis (Linn 1758)
}

\section{Gerard Lee Lo See ${ }^{1 *}$, Yolanda Chua Deliman ${ }^{1}$, Florencio Villester Arce Jr ${ }^{1}$ and Anthony Ilano ${ }^{2}$}

${ }^{1}$ Department of Pharmacy, University of San Carlos, Nasipit Talamban, Cebu City, Philippines

${ }^{2}$ Department of Biology, University of San Carlos, Nasipit, Talamban, Cebu City, Philippines

\begin{abstract}
Gastropod mucus has been shown to possess antibacterial and antitumorcidal properties. Melo broderipii and Lambis lambis are two gastropods abundant in the Philippines and claimed to have antibacterial and antioxidant properties but no available data yet on its cytotoxic and genotoxic effects. The aim of this study was to evaluate, for the first time, the cytotoxic and genotoxic effect of mucus from Melo broderipii and Lambis lambis. For cytotoxic effect determination, microscopic observation for cell arrest, cell bursting and morphological distortion of the developing sea urchin embryo and quantification of affected zygotes were conducted. For genotoxic effect determination, root length measurement and microscopic observation for chromosomal aberration of onion root tip were conducted. Results for cytotoxic effect showed that Melo broderipii mucus $(80 \% \mathrm{v} / \mathrm{v})$ test solution (TS) had $70 \%$ cytotoxic activity while Lambis lambis ( $80 \% \mathrm{v} / \mathrm{v}) \mathrm{TS}$ had $65 \%$ cytotoxic activity. Cell arrest $(40 \%)$ was the most prominent parameter for both test solutions. For genotoxic effect, Melo broderipii mucus (100\% v/v) elicited root growth of $0.244 \mathrm{~cm}$ while Lambis lambis mucus $(100 \% \mathrm{v} / \mathrm{v})$ exhibited root growth of $0.367 \mathrm{~cm}$. Bridges and fragments of chromosomes were observed in $100 \%$ TS of Melo broderipii while vargrants and binucleated chromosomes in $100 \%$ TS of $L$. lambis. Alkaloids, terpenes and proteins present in the mucus of Melo broderipii and Lambis lambis account for the cytotoxic and genotoxic effects.
\end{abstract}

Keywords: Melo broderipii; Lambis lambis; Gastropod mucus; Cytotoxic and genotoxic studies; Embryonic development of sea urchin

\section{Introduction}

Plants and terrestrial microorganisms, especially those from soil samples, have traditionally been in the focus for the search for new drug candidates from nature. Due to the repeated re-isolation of already known compounds, the emphasis in the search for new drug-like chemical entities is nowadays shifting to less investigated organisms from unique habitats such as the sea. Contrary to the terrestrial environment where plants are the most prolific sources of natural products, in the sea this key position is kept by invertebrates such as sponges, tunicates, shell, molluscs and others [1-3].

In a previous study on gastropod mucus, the isolation of achacin from the body mucus of the giant African land snail Achatina fulica suggests mucus also provides a chemical barrier. Achacin is an L-amino oxidase that generates $\mathrm{H}_{2} \mathrm{O}_{2}$ from oxidative deamination of L-lysine and L-arginine and has antibacterial and tumoricidal properties [4]. Gastropods such as Melo broderipii and Lambis lambis secrete mucus which has been shown to have many functions, such as aiding locomotion, feeding, protection, and settlement. Mucus is a gel consisting of a polymer network that functions as a protective layer for the integument and mucosal surfaces of both simple animals and mammals. Mucus is produced by glands of the marine snail's foot, specifically a large gland located below the mouth. Since one of the functions of the mucus is for protection, it might contain certain secondary metabolites that have the potential for toxicity. The two gastropods are widely found in the Philippines and had claims of antibacterial and antioxidant properties. However, no studies have been conducted yet for its cytotoxic and genotoxic effects. Thus, these marine species were used as samples in this study [5].

Based on the World Health Organization (WHO) records, cancers figure among the leading causes of morbidity and mortality worldwide $[6,7]$. In response, biomedical scientists are intensifying their efforts to look for more sources of drugs that are effective against many types of cancer [8]. The majority of drugs used for the treatment of cancer today are cytotoxic (cell-killing) drugs that work by interfering in some way with the operation of the cell's DNA, inhibition of DNA synthesis and thus prevention of cell division. Cytotoxic drugs have the potential to be very harmful to the body unless they are very specific to cancer cells-something difficult to achieve because of the modifications that change a healthy cell into a cancerous one are very subtle. Numerous toxicities are associated with the currently available cytotoxic drugs. More importantly, many cancers are inherently resistant to these drugs or become so during prolonged treatment resulting to multidrug resistance [9]. A major challenge is to search and design new drugs that would be more selective for cancer cells, and thus have lesser side effects.

For several years, embryos and eggs of sea urchin have been used as a model for studying cell division and embryologic development. Also, this model has been utilized to detect the cytotoxic and teratogenic activities of new compounds [10,11]. Recently, some works have emphasized the study of alterations in sea urchin egg development as a multicellular model for evaluating cytotoxic activity. Sea urchins are echinoderms and the pattern of their embryonic development is nearly similar to that of the phylum chordate, where human beings belong to [12]. Moreover, among the various tests available for genotoxic studies, those that use onion chromosome are extremely useful, relatively inexpensive and can easily be handled. Also, there is a great contact surface proportioned by bulbs in the aqueous extracts administered. In addition, these species also show high sensitivity to toxic compounds and they don't have small chromosomes, increasing their application for cytogenetic studies [13].

*Corresponding authors: Gerard Lee Lo See, Department of Pharmacy, University of San Carlos, Nasipit Talamban, Cebu City, Philippines, Tel: 63322300100; E-mail: gerseeph1990@yahoo.com

Received June 29 2016; Accepted July 13, 2016; Published July 18, 2016

Citation: See GLL, Deliman YC, Arce JFV, Ilano A (2016) Cytotoxic and Genotoxic Studies on the Mucus of Indian Volute Melo broderipii (Gmelin 1758) and Spider Conch Lambis lambis (Linn 1758). J Pharmacogn Nat Prod 2: 120. doi:10.4172/2472-0992.1000120

Copyright: ( 2016 See GLL, et al. This is an open-access article distributed under the terms of the Creative Commons Attribution License, which permits unrestricted use, distribution, and reproduction in any medium, provided the original author and source are credited. 
This study aimed to determine the genotoxic activity of the mucus as indicated by bridges, fragments, laggards, vagrants on the abraded onion root tip cells upon microscopic examinations. Moreover, determine the mucus concentration that may provide the maximum cytotoxic effect, exhibited by the number of developing sea urchin zygotes affected as indicated by cell arrest, cell bursting and morphological distortion. Lastly, determine percent cytotoxic activity of the Melo broderipii and the Lambis lambis mucus.

\section{Materials and Methods}

\section{Collection of mucus}

The Indian volute was purchased from Cataingan, Masbate, Philippines. The Spider conch was purchased from the Marine Biology Research Marine Biology Research Center, Cebu, Philippines. The shells were authenticated by the University of San Carlos-Department of Biology. Shells were exposed to dryness for 60 minutes. Mucus secretions were then collected by plankton net scoop and placed in culture tubes.

\section{Preparation of test solutions}

Three different test solution concentrations, $10 \% \mathrm{v} / \mathrm{v}, 50 \% \mathrm{v} / \mathrm{v}$, and $80 \% \mathrm{v} / \mathrm{v}$, of the mucus from each shell were prepared for the cytotoxic effect determination and $10 \% \mathrm{v} / \mathrm{v}, 50 \% \mathrm{v} / \mathrm{v}$ and $100 \% \mathrm{v} / \mathrm{v}$ were the concentrations for the genotoxic effect determination. For the cytotoxic effect determination, each concentration was prepared by diluting the mucus with sufficient amount of previously boiled and filtered sea water to reach the desired concentration. For the genotoxic effect determination, each concentration, except for the $100 \% \mathrm{v} / \mathrm{v}$, was prepared by diluting the mucus with sufficient amount of distilled water.

\section{Secondary metabolite chemical screening using test tube method}

One millilter of the pure Melo broderipii and Lambis lambis mucus were tested for the presence of deoxysugars, tannins, alkaloids, sterols, flavonoids, lactones, terpenes, reducing sugars and saponins [14].

\section{Cytotoxic effect determination}

Artificial induction of edible sea urchins was used to observe their embryonic development. The embryonic development was closely observed for eight hours. Three trials in triplicates were conducted for this part of the study. The method involved several major procedures listed below [15].

Collection of sea urchin: Thirty mature sea urchins (Tripneustes gratilla Linn.) were collected from the University of San Carlos-Marine Biology Research Station, Maribago, Lapu Lapu City, Philippines. They were authenticated by the University of San Carlos-Marine Biology Section.

Sexing of sea urchin: A $5 \mathrm{~mL}$ syringe was used to collect gonad sample from the sea urchin on the Aristotle's lantern pointing directly to the roe. Collected gametes were examined and assessed using the naked eye to determine the sex. Orange colored gametes indicated a female sea urchin while white colored gametes indicated a male sea urchin.

Spawning induction: After determining the sex of the sea urchin, their Aristotle's lanterns were removed carefully by dissecting with scissors and tweezers without injuring the gonads. Contents of intestinal tracts were washed away from coelom with previously boiled and filtered sea water. Then, each sea urchin was placed on the top of a beaker ( $200 \mathrm{~mL}$ capacity) filled with sea water, with its genital openings downward (mouth removal method). Potassium chloride solution (2 $\mathrm{mol}$ ) was injected to induce further releasing of gametes.

Artificial fertilization: The eggs and sperm were separately counted under a digital microscope (T-1901 KEN-A-VISION, USA) to reach a ratio of 1 egg cell: 4 sperm cells. After counting, the eggs were transferred to a $1000-\mathrm{mL}$ beaker and were inseminated with suitable amount of sperm collected from several males. The mixture was stirred gently using a glass stirrer and allowed to stand for 30-60 minutes for the fertilization to occur. The fertilized egg/zygote developed into series of cleavages, 2, 4, 8, 16, 32, 64 cell-stage and Morula stage. Transfer using a pipette $30 \mathrm{~mL}$ of the egg and sperm mixture to a 125 $\mathrm{mL}$ Erlenmeyer flask. During the formation of cleavages, the mucus extract was introduced to the developing embryo and the reproduction process was observed e.g. arrest, bursting morphological distortion.

Observation and quantification of the developing zygote: Newly fertilized eggs were observed quantitatively under a digital microscope (T-1901 KEN-A-VISION, USA). Each of the three concentrations, $10 \%, 50 \%$ and $80 \%$, was introduced using a pipette to a developing sea urchin embryo contained in a beaker. The different developmental stages: The Early Cleavage, which is subdivided into 2, 4, 8 and 16 cleavages, was observed every 30 minutes. The Late Cleavage, which has 32, 64 and 128 cleavages, was observed every hour. The Morula, Blastula, and Gastrula stages which were subdivided into early and late sub-stages were observed every 2, 3 and 6 hours respectively. Each stage was observed according to the required number of time. For early cleavage, observation, a sample from the mixture of fertilized egg was obtained 30 minutes after artificial fertilization. For Morula, Blastula and Gastrula stages observations, a sample from the same mixture of fertilized egg was obtained 2, 3, and 6 hours respectively after artificial fertilization.

For each stage, a drop from each mixture was obtained and placed in a depression slide and viewed under microscope. The field of the slide was videotaped and counted for the total number of affected zygotes. The percentage of the affected zygotes was then determined. An indication of its cytotoxicity was arrest, bursting or morphological distortion of the developing zygotes. An indication of cell arrest is when a developing cell ceases to proceed to the next developing stage. A table was made to record all observations for each stage. Every concentration has a separate table as well as the normal control, which was sea water.

$$
\% \text { cytotoxic activity }=\frac{\text { no. of affected zygote per drop }}{\text { total number of zygotes per drop }} \times 100
$$

Determination of median lethal concentration $\left(\mathrm{LC}_{50}\right)$ : A linear regression analysis was used to obtain a linear equation (through Microsoft Excel 2007 edition) that was then used to calculate the $\mathrm{LC}_{50}$. It was calculated using this formula: $\mathrm{y}=\mathrm{mx}+\mathrm{b}$.

\section{Genotoxic effect determination}

A total of 45 onions were used in the study for the three trials with three different concentrations in triplicates. After that, Sample was checked under the microscope if there were any micronuclei or aberrations using theoretical pictures as the standard. Methyl methanesulfonate $(10 \mathrm{mg} / \mathrm{L})$ (SIGMA-ALDRICH, USA) and distilled water were used as the positive and negative control respectively [16].

Pre-treatment and exposition of testing organism: All Onion roots were removed prior to exposition to the cultivation medium 
Citation: See GLL, Deliman YC, Arce JFV, Ilano A (2016) Cytotoxic and Genotoxic Studies on the Mucus of Indian Volute Melo broderipii (Gmelin 1758) and Spider Conch Lambis lambis (Linn 1758). J Pharmacogn Nat Prod 2: 120. doi:10.4172/2472-0992.1000120

Page 3 of 7

\begin{tabular}{|c|c|}
\hline Chemical & Concentration $\mathbf{( m g / L )}$ \\
\hline Calcium sulfate $^{*}$ & 60 \\
\hline Magensium sulfate & 60 \\
\hline Sodium bicarbonate & 96 \\
\hline Potassium chloride & 4 \\
\hline
\end{tabular}

'Dissolve calcium with heating and stirring before it is mixed with other salts Note: $\mathrm{pH}$ of the cultivation and tested sample should be between 5.5 and 8 . If needed, adjust the $\mathrm{pH}$ with $1 \mathrm{M} \mathrm{HCl}$ or $\mathrm{NaOH}$ to 7

Table 1: Composition of Allium cepa cultivation medium.

(Table 1) for first 24 hours. The individual onions were placed onto round glass containers and onions were suspended in sticks allowing the base of the onion to be immersed on the medium. The set-up was then exposed to sunlight for 12 hours and another 12 hours in the dark. After 24 hours, the size of the root growth was measured using a ruler from the end of the bulb to the root tip. The root which had the highest growth was considered. The rest of the root tips were cut leaving only one root tip. The onion bulbs were exposed to the test solutions and controls for 48 hours. After 48 hours, the root growth was measured using a ruler from the end of the bulb to the root tip.

Maceration of the root tips and preparation for microscopy: After exposition, the root tip with the least percent root growth from each concentration was selected for microscopy. A root tip about $1 \mathrm{~cm}$ long was cut and transferred into a plastic micro-tube. Using a dropper, the micro-tube was $2 / 3$ filled with $1 \mathrm{~N} \mathrm{HCl}$. The tubes were placed in $60^{\circ} \mathrm{C}$ water bath, and allowed the roots to soak for 12 minutes. After 12 minutes soaking period, the root tips were rinsed three times with distilled water. After removing the third rinse, the root was covered with Feulgen stain. The roots were incubated in the stain for 12 minutes. Then, the stain was removed and the root tip was rinsed with distilled water thrice. The root tip was cut thinly using a microtome then fixed in a glass slide for microscopic examination.

Microscopic examination: The prepared slides were then examined under a compound light microscope for any aberrations and compared them with the standard pictures.

Calculation of percent root growth: Percent root growth was computed using the equation below:

$$
\% \text { Root Growth }=\frac{[(\text { R.G.in culture medium })-(\text { R.G.in test solution })]}{[(\text { R.G.in culture medium })-(\text { R.G.in negative control })]} \times 100
$$

\section{Results}

\section{Cytotoxic effect determination}

Figures 1 and 2 show the percent cytotoxic activity of Melo broderipii and Lambis lambis, respectively. The highest tested concentration $(80 \%)$ of both samples shows the highest percentage of affected zygotes (cell arrest, bursting, morphological distortion) in all developmental stage. The cytotoxic activities of Melo broderipii and Lambis lambis test solutions were concentration dependent. As the concentration of the test solution increases, the cytotoxic effect increases as well. Both test samples showed similar pattern for its cytotoxic activity.

Furthermore, in terms of the total number of affected zygotes based on the parameters of cell arrest, cell bursting and morphological distortion. Figure 3 shows that at least $40 \%$ of cell arrest, $2 \%$ cell bursting and $0.5 \%$ morphological distortion were observed for each cell stage of the Melo broderipii mucus test solution. Figure 4, Lambis lambis test solution, also shows approximately similar results with
Melo broderipii. Among the three parameters, cell arrest was the most notable abnormality in the embryonic development of sea urchin (Figures 5a \& 5b).

\section{Median lethal concentration $\left(\mathrm{LC}_{50}\right)$}

The computed $\mathrm{LC}_{50}$ for Melo broderipii test solution were $50.22 \%$, $49.09 \%, 51.58 \%, 46.02 \%, 44.60 \%$, and $57.55 \%$ for 2 -cell stage, 4 -cell stage, 8-cell stage, 16-cell stage, and 32-cell stage, respectively. The r-value was 0.9 for all cell stages.

The computed $\mathrm{LC}_{50}$ for Lambis lambis test solution were $57.57 \%$, $49.20 \%, 50.18 \%, 50.31 \%, 42.00 \%$, and $55.23 \%$ for 2 -cell stage, 4 -cell stage, 8 -cell stage, 16-cell stage, 32 -cell stage, respectively. The r-value was 0.9 for all cell stages.

Computed median lethal concentration signifies the concentration of the test solution which is sufficient to cause arrest, bursting or morphological distortion on each stage of the embryonic development. The r-value is the correlation factor between the two variables, namely, concentration and percent cytotoxicity. An r-value of near one would mean perfect correlation. As the concentration of the test solution increases, the percent cytotoxicity increases as well. There is a direct relationship between concentration and percent cytotoxicity in this study.

\section{Genotoxic effect determination}

The $100 \%$ concentration of the test solution for both samples shows the highest root growth inhibition while the lowest concentration shows the lowest root growth inhibition. Concentration and root growth are inversely proportional as shown in the results of the experiment. As the concentrations of the test solutions increased, the shorter is the root growth of the onion roots (Figure 6 and 7). Figure 8 shows the microscopic examination of the $100 \%$ Melo broderipii and

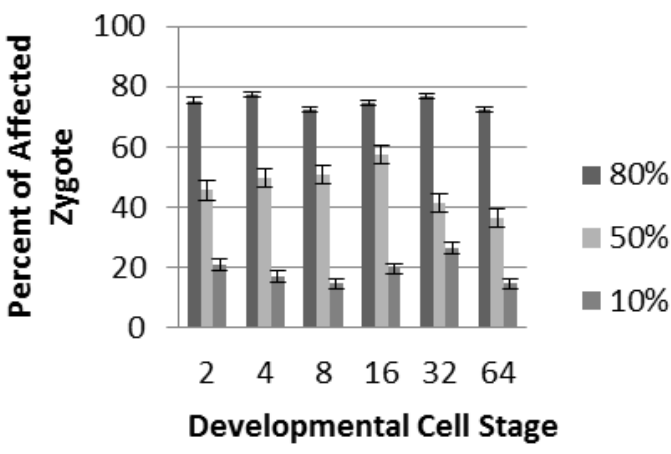

Figure 1: Percent cytotoxic activity of Melo broderipii.

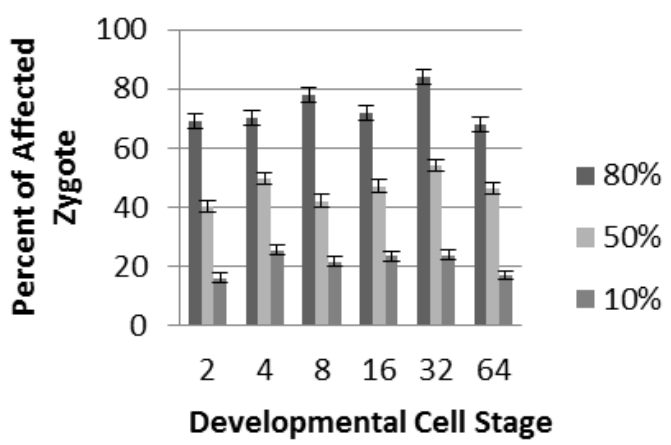

Figure 2: Percent cytotoxic activity of Lambis lambis. 
Citation: See GLL, Deliman YC, Arce JFV, Ilano A (2016) Cytotoxic and Genotoxic Studies on the Mucus of Indian Volute Melo broderipii (Gmelin 1758) and Spider Conch Lambis lambis (Linn 1758). J Pharmacogn Nat Prod 2: 120. doi:10.4172/2472-0992.1000120

Page 4 of 7

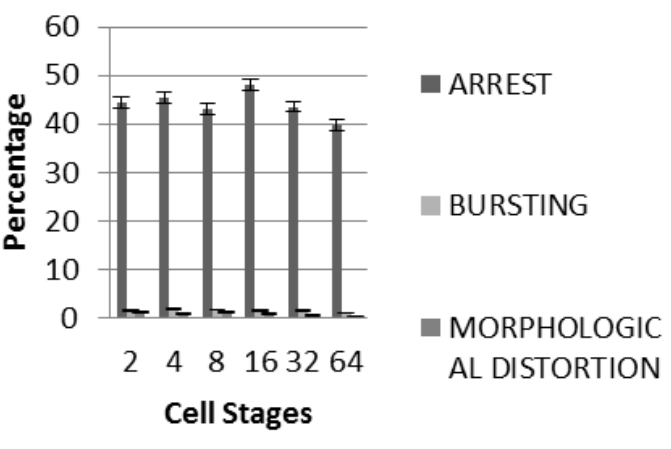

Figure 3: Melo broderipii percentage of affected zygotes.

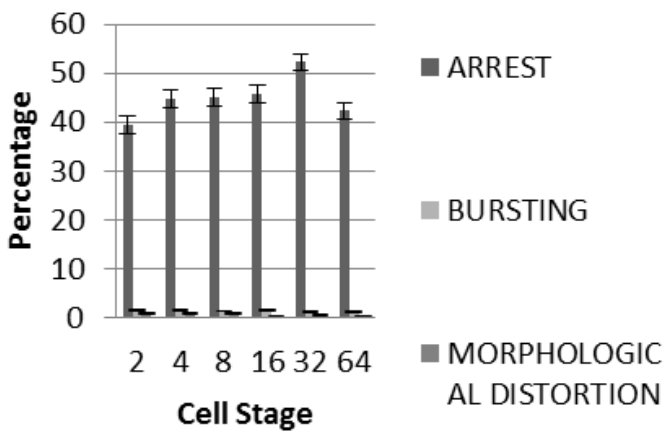

Figure 4: Lambis lambis percentage of affected zygotes.

of the Lambis lambis. The roots with the highest inhibition of growth were subjected to microscopy, bridges and fragments of chromosomes were found in $100 \%$ test solution of Melo broderipii while vagrants and binucleated chromosomes were observed in $100 \%$ test solution of Lambis lambis.

\section{Secondary metabolite chemical screening using test tube reaction method}

Both Melo broderipii and Lambis lambis mucus samples tested positive for the presence of alkaloids as indicated by an orange precipitate using Mayer's test; terpenes as indicated by a reddish brown at the interface using Salkowski's test and proteins as indicated by a violet precipitate using Biuret test.

\section{Discussion}

Cytotoxic effect determination was done by observing the embryonic development of edible sea urchin (Tripnuestes gratilla Linne). Embryo and eggs of sea urchin have been used as a model for studying cell division and embryologic development for several years. This model has also been utilized to detect the cytotoxic and teratogenic activities of new compounds $[10,11]$. At fertilization, egg undergoes a complex series of morphological, physiological, biochemical and, in many cases, morphogenetic changes that ultimately lead to differentiation of the new individual [17]. During these complex processes, the physical appearances of the cells were being evaluated for any abnormalities.

In this investigation, cytotoxicity was prominent in the mucus extract from Melo broderipii and Lambis lambis. Cell arrest, a phenomenon wherein the developing cell ceases to proceed to the next developmental stage, was the main mechanism by which the mucus exhibited its cytotoxic action.
It has also been noted that the percent cytotoxic activity of the mucus obtained from the two molluscs were concentration dependent. The R-values based on the linear equation was 0.9 for each developmental stage. This gives the association of the two variables being determined in the graph which is the percent cytotoxicity and concentration of the test solution. An R-value near one would mean a perfect correlation between percent cytotoxicity and concentration of the test solution. As the concentration of the test solutions increases, the percent cytotoxicity follows as well.

Genotoxic effect determination was done using onion chromosome aberration assay through root growth test. Onion chromosomes are extremely useful and are relatively inexpensive and can easily be handled. Also, there is a great contact surface proportioned by bulbs in the test solutions. Moreover, these onion show high sensitivity to toxic compounds and chromosomes are large enough to be seen under the microscope, increasing their application for cytogenetic studies [13].

Based on the data, genotoxicity was prominent in $100 \%$ test solution, for both molluscs, had the least root growth which would mean that there was an inhibition of root growth by the highest tested

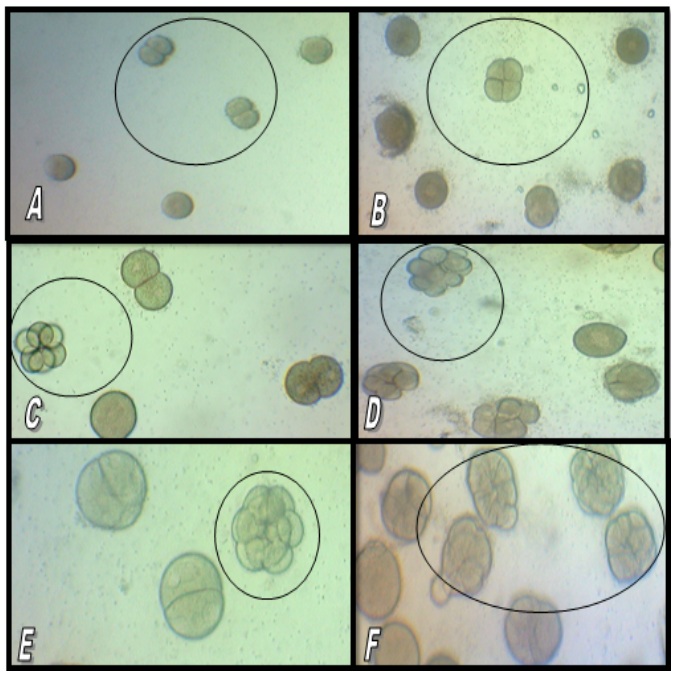

Figure 5a: Images for cell arrest. A: 2-cell stage; B: 4-cell stage; C: 8-cell stage; D: 16-cell stage; E: 32-cell stage; F: 64-cell stage. Note: Encircled are normal cells.

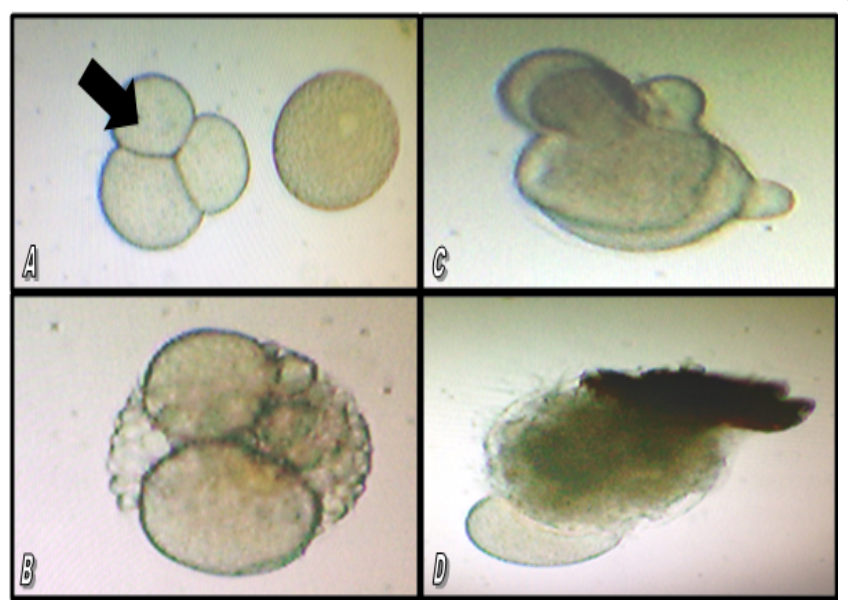

Figure 5b: Images for morphological distortion and cell bursting. A and B: Morphological distortion; C and D: Cell bursting. 


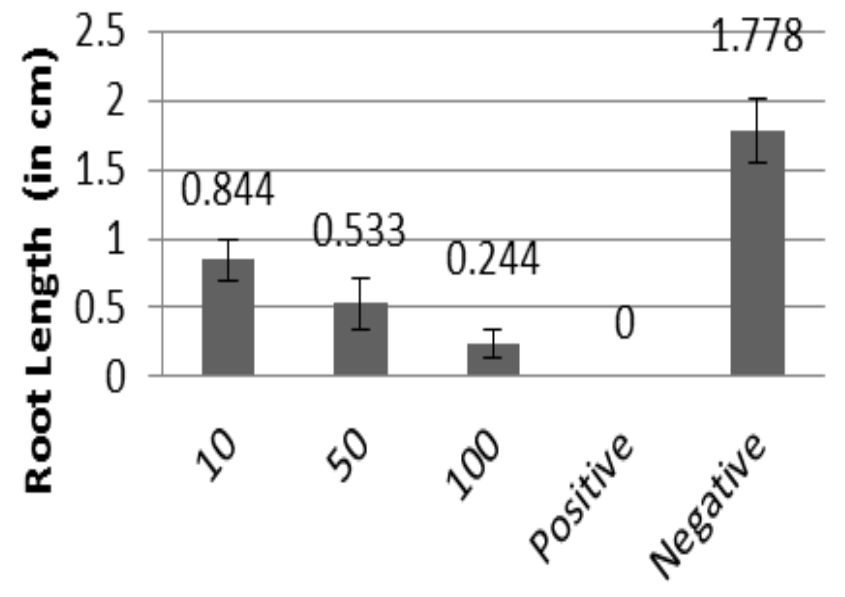

Concentration (\%) and Control

Figure 6: Melo broderipii mean root growth (in $\mathrm{cm}$ ).

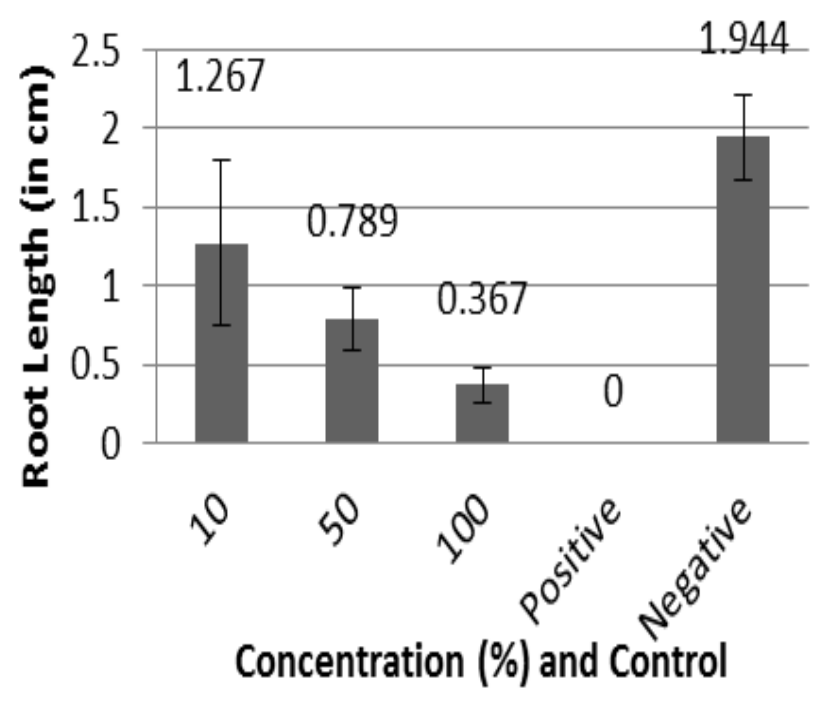

Figure 7: Lambis lambis mean root growth (in $\mathrm{cm}$ ).

concentration. The $50 \%$ had the second highest root growth while the $10 \%$ test solutions had the highest root growth among the three test solution. The study revealed that Melo broderipii 100\% mucus caused formation of bridges and fragments in chromosomes while Lambis lambis $100 \%$ mucus caused formation of vagrants and binucleated chromosomes.

Molluscs like Melo broderipii and Lambis lambis produce mucus to cover their soft body and as natural chemical protective barriers that prevent damage of the underlying tissues, body fluid losses and the infections of pathogenic microorganisms and parasites [18]. Moreover, mucus of molluscs can deter predatory attacks because they contain distasteful and deterrent compounds. Mucus can have a mechanical protective effect. It can also carry chemical cues, thereby enhancing the persistence of the chemicals and reducing their dispersal in water. Mucus also contain chemical deterrents, as shown for shelled gastropods and nudibranchs which may be attributed to the observed cytotoxic and genotoxic effects. Many of these deterrents are diet-derived and not synthesized de novo, and many are terpenoids, especially sesquiterpenoids and diterpenoids [19]. The origin of natural products found in marine invertebrates is often not clear. Microorganisms that either live inside their invertebrate hosts or that are derived through the food chain have been suggested to be potential producers of some of the secondary metabolites that are recovered from sponges, tunicates and other molluscs.

Mucus of these molluscs showed cytotoxic and genotoxic activity which may be useful in chemotherapy in the future, however, further studies needs to be conducted. Genotoxic effect determination showed that the pure mucus of the gastropods was able to cause chromosomal damage such as bridges, fragments, vagrants and binucleated cells. Chromosmal fragments can be derived from chromosomal breakages caused by clastogenic effects induced by the test solutions or spontaneously from chromosomal aberrations, such as chromosomal bridges, which break up and originate acentric fragments [20]. Chromosomal damage may be one of the underlying mechanisms contributing to the observed cell arrest in the cytotoxic effect determination since chromosomal integrity and cell proliferation are interrelated. The maintenance of genome stability is essential for normal cell proliferation. Genome stability is threatened by genotoxic agents that damage DNA, resulting in the direct or indirect induction of DNA breaks. DNA damage can activate checkpoint pathways that lead to cell cycle arrest in the G1, S or G2 phases of the cell cycle. DNA breaks can occur after an interference with the DNA replication machinery. Inhibition of the elongation stage of DNA replication activates the replication checkpoint which is closely related to the S phase DNA damage checkpoint, and leads to cell cycle arrest [21]. Moreover, when a prometaphase cell returns to interphase without undergoing anaphase, it can elicit subsequent cell death or growth arrest [22].

Melo broderipii and Lambis lambis mucus contain alkaloids, terpenes and proteins which may be responsible for the elicited cytotoxic and genotoxic effects. Alkaloids are naturally occurring nitrogen containing biologically active heterocyclic compounds. Several types of marine alkaloids have been identified based on literatures. Pyridoacridines are highly coloured marine natural products having polycyclic planar heteroaromatic $11 \mathrm{H}$-pyrido[4,3,2,mn]acridine system. They are probably the largest class among marine alkaloids and are almost universally isolated from mollusc. Pyridoacridine alkaloids show significant biological activity primarily cytotoxicity and certain specific biological properties such as fungicidal and bactericidal properties, inhibition of topoisomerase II, anti HIV, intercalation of DNA property, $\mathrm{Ca}^{2+}$ releasing activity, and production of reactive oxygen species. Another type of alkaloid which can be found in marine invertebrate is indole-containing alkaloid. Indole alkaloids show different type of biological activities such as cytotoxic, and antitumor activities [23]. Furthermore, Terpenoids (also called "isoprenoids") are secondary metabolites occurring in most organisms. Terpenoids exhibit cytotoxicity against a variety of tumor cells and cancer preventive as well as anticancer efficacy in preclinical animal models. Epidemiological and experimental studies suggest that monoterpenes may be helpful in the prevention and therapy of several cancers, including mammary, skin, lung, forestomach, colon, pancreatic and prostate carcinomas. Numerous preclinical efficacy studies have provided extensive evidence that both naturally occurring and synthetic derivatives of triterpenoids possess chemopreventive and therapeutic effects against colon, breast, prostate and skin cancer. These triterpenoids and their derivatives act at various stages of tumor development, inhibit initiation and promotion of carcinogenesis, induce tumor cell differentiation and 
Citation: See GLL, Deliman YC, Arce JFV, Ilano A (2016) Cytotoxic and Genotoxic Studies on the Mucus of Indian Volute Melo broderipii (Gmelin 1758) and Spider Conch Lambis lambis (Linn 1758). J Pharmacogn Nat Prod 2: 120. doi:10.4172/2472-0992.1000120

Page 6 of 7

\section{Actual Photo Theoretical Photo}

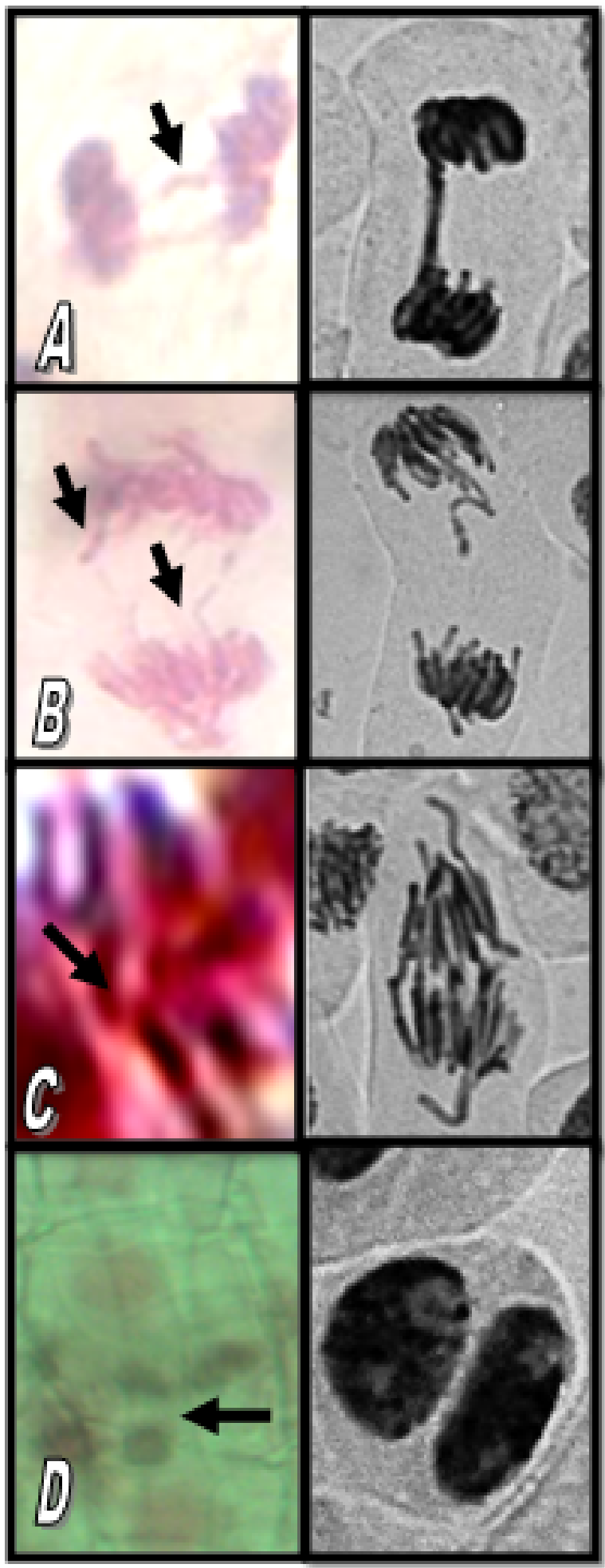

[A: Bridges (100\% Melo broderipii); B: Fragments (100\% Melo broderipii) C: Vagrants (100\% Lambis lambis); D: Binucelated (100\% Lambis lambis)] Theoretical photo taken from: Kalcheva et al., 2009 (http://www.scielo.br/pdf/ gmb/v32n2/a28v32n2.pdf)

Figure 8: Microscopy of onion root tips. apoptosis, and suppress tumor angiogenesis, invasion and metastasis through regulation of various transcription and growth factors as well as intracellular signaling mechanisms [24]. Lastly, proteins from marine animals such as molluscs have been shown to have cytotoxic effect on several human cancer cell lines [11]. Moreover, a protein isolated from mucus of sea slugs which belong to the Gastropoda class possesses cytotoxicity. A $56-\mathrm{kDa}$ protein (cyplasin) isolated from the mucus of the European sea hare Aplysia punctata shows a preferential toxicity to autonomously growing transformed mammalian cells [25].

Melo broderipii and Lambis lambis mucus contains alkaloids, terpenes and proteins which may be responsible for the cytotoxic and genotoxic effects.

With these preliminary results, the researchers recommend the determination of isoenzyme expression of the test organisms using electrophoresis to further confirm any abnormalities at a molecular level. Isolation and purification of alkaloids, terpenes and proteins from the mucus of these two gastropods and conduct further tests using human cancer cell lines and identify which phase of cell cycle will the gastropods induce arrest.

\section{Acknowledgements}

The researchers would like to thank the University of San Carlos-Department of Pharmacy for their unending support in this endeavor. Mrs. Nelly Nonette M. Ouano, Mrs. Elizabeth Y. Tan, Mrs. Rosie L. Barrientos, Mrs. Loujessa D. Arcelo, Mr. Paul Geraldino, Ms. Megan Aubrey Yu for their technical assistance and suggestions valuable in this study.

\section{References}

1. Penesyan A, Kjelleberg S, Egan S (2010) Development of novel drugs from marine surface associated microorganisms. Mar Drugs 8: 438-459.

2. Ebada SS, Proksch $P$ (2011) Marine organisms and their prospective use in therapy of human disease. In: Melhorn H (eds.) Nature helps How Plants and Other Organisms Contribute to Solve Health Problems. Berlin Heidelberg Springer Verlag, Germany, pp: 153-190.

3. Chapman AD (2009) Number of living species in Australia and the world (2 edn.) Commonwealth of Australia, Australia.

4. Loker ES (2010) Gastropod immunobiology. In: Söderhäll K (eds.) Invertebrate Immunity. Landes Bioscience and Springer Science Business Media. Germany.

5. Carpenter KE, Niem VH (1998) FAO species identification guide for fishery purposes. Food and Agriculture Organization of The United Nations.

6. http://www.who.int/mediacentre/factsheets/fs297/en/

7. https://quintessentialy.wordpress.com/2010/02/08/doh-says-breast-cancer-isleading-cause-of-cancer-deaths-in-rp/

8. Rodriguez MP (2006) Bioassay-guided isolation and characterization of anticancer metabolites of sponge-associated alpha-proteobacteria (SPE-17) University of San Carlos.

9. Rowinsky EK (1997) The development and clinical utility of the taxane class of antimicrotubule chemotherapy Agents. Annu Rev Med 48: 353-374.

10. Hansen E, Eilersten HC, Ernstsen A, Geneviere A (2003) Anti-mitotic activity towards sea urchin embryos in extracts from the marine haptophycean Phaeocystis pouchetii (Hariot) Lagerheim collected along the coast of northern Norway. Toxicon 41: 803-812.

11. Suarez-Jimenez GM, Burgos-Hernandez A Ezquerra-Brauer JM (2012) Bioactive peptides and depsipeptides with anticancer potential: sources from marine animals. Mar Drugs 10: 963-986.

12. Lotufo LVC, Khan MTH, Ather A, Wilke DV, Jimenez PC, et al (2005) Studies of the anticancer potential of plants used in Bangladeshi folk medicine. Journal of Ethnopharmacology 99: 21-30.

13. Saulo S, Silva PS, Campos JMS, Viccini LF (2009) Cytotoxic and genotoxic effects of two medicinal species of Verbenaceae. Caryologia 62: 326.

14. Guevara BQ (2005) A guidebook to plant screening: phytochemical and biological. University of Santo Tomas Publishing House. 
Citation: See GLL, Deliman YC, Arce JFV, Ilano A (2016) Cytotoxic and Genotoxic Studies on the Mucus of Indian Volute Melo broderipii (Gmelin 1758) and Spider Conch Lambis lambis (Linn 1758). J Pharmacogn Nat Prod 2: 120. doi:10.4172/2472-0992.1000120

15. Ilano A (2007) University of San Carlos, Cebu City, Philippines (Personal Communication)

16. Feretti D, Zerbini I, Zani C, Ceretti E, Moretti M, et al (2007) Allium cepa chromosome aberration and micronucleus tests applied to study genotoxicity of extracts from pesticide-treated vegetables and grapes. Food Addit Contam 24: $561-572$

17. Tyler A (1957) The Beginnings of embryonic development. American Association for the Advancement of Science.

18. Gliński Z, Jarosz J (1997) Molluscan immune defenses. Arch Immunol Ther Exp (Warsz) 45: 149-155.

19. Derby C (2007) Escape by inking and secreting: marine molluscs avoid predators through a rich array of chemicals and mechanisms. Biol Bull 213 274-289.

20. Gupta AK, Ahmad M (2012) Assessment of cytotoxic and genotoxic potential of refinery waste effluent using plant and animal system. J Hazard Mater 201 202: 92-99.

21. Szüts D, Krude $T$ (2004) Cell cycle arrest at the initiation step of human chromosomal DNA replication causes DNA damage. J Cell Sci 117: 4897-4908.

22. Dalton WB, Nandan MO, Moore RT, Yang VW (2007) Human cancer cells commonly acquire DNA damage during mitotic arrest. Cancer Res 67:1148711492.

23. Kumar D, Rawat DS (2011) Marine natural alkaloids as anticancer agents. Opp Chall Scope Nat Prod Med Chem 37: 213-268.

24. Thoppil RJ, Bishayee A (2011) Terpenoids as potential chemopreventive and therapeutic agents in liver cancer. World J Hepatol 3: 228-249.

25. Petzelt C, Joswig G, Stammer H, Werner D (2002) Cytotoxic cyplasin of the sea hare, Aplysia punctata, cDNA Cloning, and expression of bioactive recombinants in insect cells. Neoplasia 4: 49-59. 